\title{
Linfoma de Burkitt en íleon terminal, en un paciente con inmunodeficiencia común variable asociada
}

\section{Burkitt Lymphoma in Terminal Ileum in a Patient with Associated Common Variable Immunodeficiency}

\author{
Bárbara Elizabeth Zannini ${ }^{1}$ Cecilia Alzugaray ${ }^{1}$ Claudio Milicchio ${ }^{1}$ Maximiliano Matteoda ${ }^{1}$ \\ Diego Quirós ${ }^{1}$
}

${ }^{1}$ Servicio de Diagnóstico por Imágenes, Imágenes MDQ, Mar del

Plata, Buenos Aires, Argentina

Rev Argent Radiol 2019;83:62-64.

Address for correspondence Bárbara Elizabeth Zannini, MD, Servicio de Diagnóstico por imágenes, Imágenes MDQ, Mar del Plata, Buenos Aires, Argentina (e-mail: barbarazannini@hotmail.com).

Estimados Editores,

El linfoma de intestino delgado representa del 20\% al 30\% de todos los linfomas gastrointestinales primarios. En la mayoría de los casos, son linfomas no Hodgkin (LNH) de células B y su localización más común es el íleon distal (60\% $-65 \%$ ) debido a la mayor cantidad de tejido linfoide. ${ }^{1,2}$

El linfoma de Burkitt (LB) es una forma agresiva de LNH de células B y representa del $1 \%$ al $5 \%$ de los LNH gastrointestinales primarios en adultos. ${ }^{3}$ Los pacientes con inmunodeficiencia común variable (IDCV), tienen riesgo elevado de desarrollar LNH de células B por mecanismos no bien conocidos en la actualidad; sin embargo, se encuentran involucrados factores genéticos relacionados con la supervivencia de los linfocitos B y deficiencias del activador transmembranal (TACI), así como desregulación inmunológica de la homeostasis de las células $\mathrm{B}$, infecciones crónicas por determinados patógenos y un aumento de la radiosensibilidad en esos pacientes. ${ }^{4}$

Describimos el caso de un paciente masculino de 41 años de edad, con antecedentes de IDCV, púrpura trombocitopénica y esplenectomía, que consultó por dolor abdominal de predominio en fosa ilíaca derecha y fiebre de varios días de evolución. El laboratorio arrojó leucocitosis y, a través de una ecografía abdominal, se observó a nivel del íleon distal un engrosamiento difuso de la pared, marcadamente hipoecogénico, con áreas ecogénicas, sugerentes de aire mural, escaso líquido libre y algunas adenopatías adyacentes menores a $15 \mathrm{~mm}$ (-Fig. 1). Se indicó tomografía computada (TC) que mostró marcado engrosamiento parietal de tipo circunferencial del íleon distal con tenue realce luego de la administración de contraste endovenoso, dilatación de la luz y

received

December 12, 2017

accepted

October 28, 2018
DOI https://doi.org/

10.1055/s-0038-1676508. ISSN 1852-9992. áreas de neumatosis en su pared. Esos hallazgos se asociaban localmente a la alteración de la densidad de la grasa, escaso líquido libre y adenopatías mesentéricas (-Fig. 2).

Dado que el paciente presentaba signos clínicos de complicación y presencia de neumatosis intestinal en los estudios por imágenes, se decidió su internación para la resección de la porción de íleon afectado y hemicolectomía derecha. Finalmente, el resultado de la anatomía patológica de la pieza operatoria reveló la existencia a nivel del íleon terminal de una lesión tumoral de tejido blanquecino con aspecto exofítico-infiltrante, que midió $13 \mathrm{~cm} \times 9 \mathrm{~cm} \times 6 \mathrm{~cm}$ y ocupaba el $100 \%$ de la circunferencia (-Fig. 3). En la microscopía óptica se observó una proliferación linfoide atípica que comprometía el espesor parietal intestinal con células de mediano tamaño, cromatina dispersa y escaso citoplasma basóphyllo, así como múltiples figuras mitóticas. Se apreciaba apariencia típica de "cielo estrellado" producida por macrófagos dispersos que contienen restos celulares apoptóticos (-Fig. 3b). La inmunohistoquímica reveló resultados positivos para infiltración por LNH tipo B, Burkitt. En el posoperatorio, el paciente evolucionó favorablemente y fue dado de alta con ciclos de quimioterapia. Reingresó con empeoramiento de su estado general y pronóstico ominoso.

Existen tres formas clínicas del LB; la endémica, la esporádica y la asociada a inmunodeficiencia. Los tres subtipos demuestran cualquiera de las tres translocaciones cromosómicas (8: 14, 8: 22 y 2: 8) y la sobreexpresión del oncogén c-Myc. Su incidencia es más alta en niños y poco común en la edad adulta. Los raros casos reportados en adultos se encuentran asociados con estados de inmunodeficiencia (incluido el VIH) e inmunosupresión. ${ }^{4-6}$
Copyright @ 2019, Sociedad Argentina de Radiología. Publicado por Thieme Revinter Publicações Ltda., Rio de Janeiro, Brazil. Todos los derechos reservados.

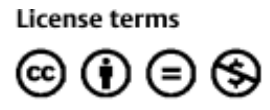




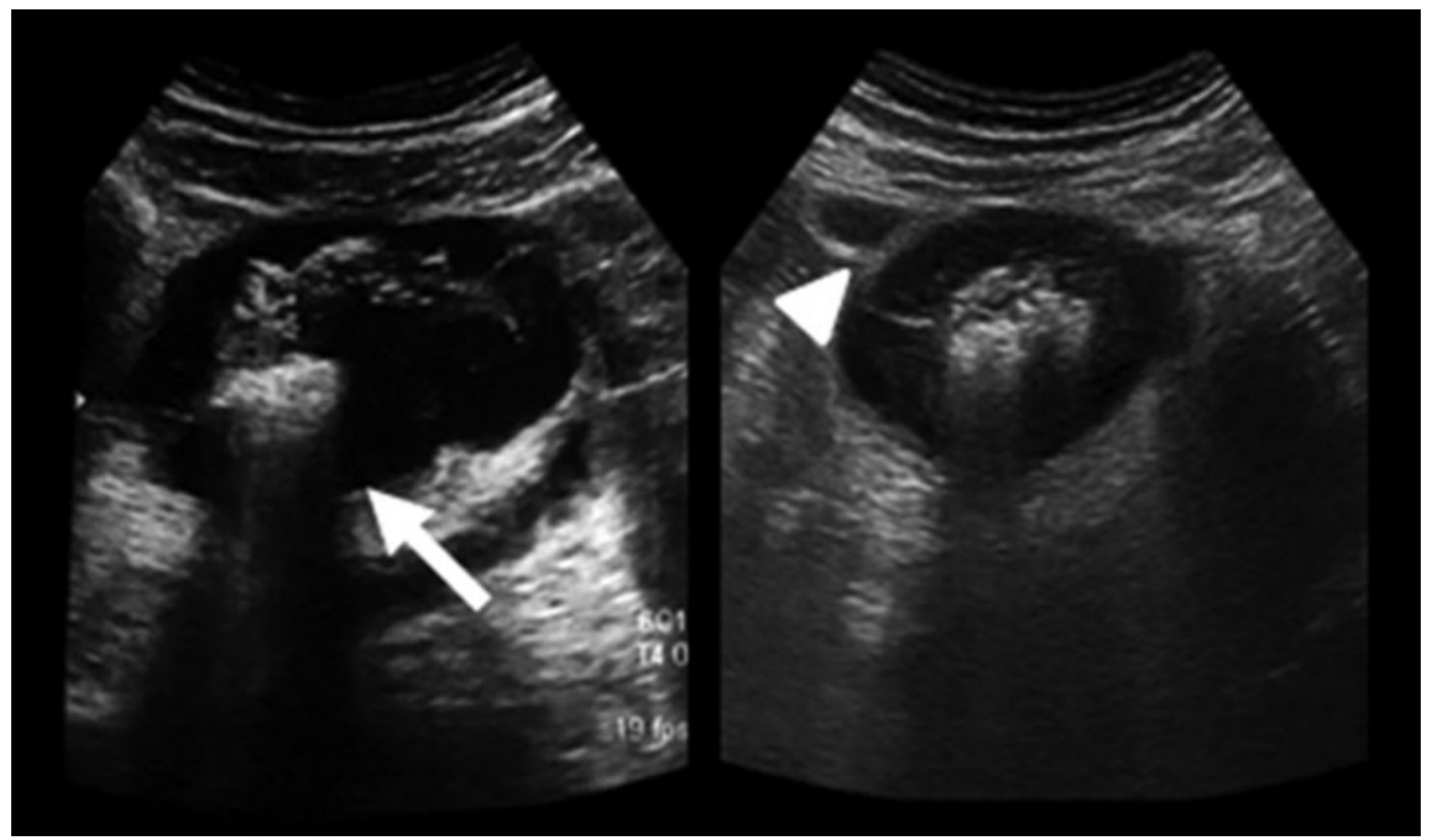

Fig. 1 Ecografía abdominal. Engrosamiento parietal difuso del íleon distal, con imagen ecogénica en pared que corresponde a aire mural (flecha) y estructura ganglionar adyacente en mesenterio (cabeza de flecha).
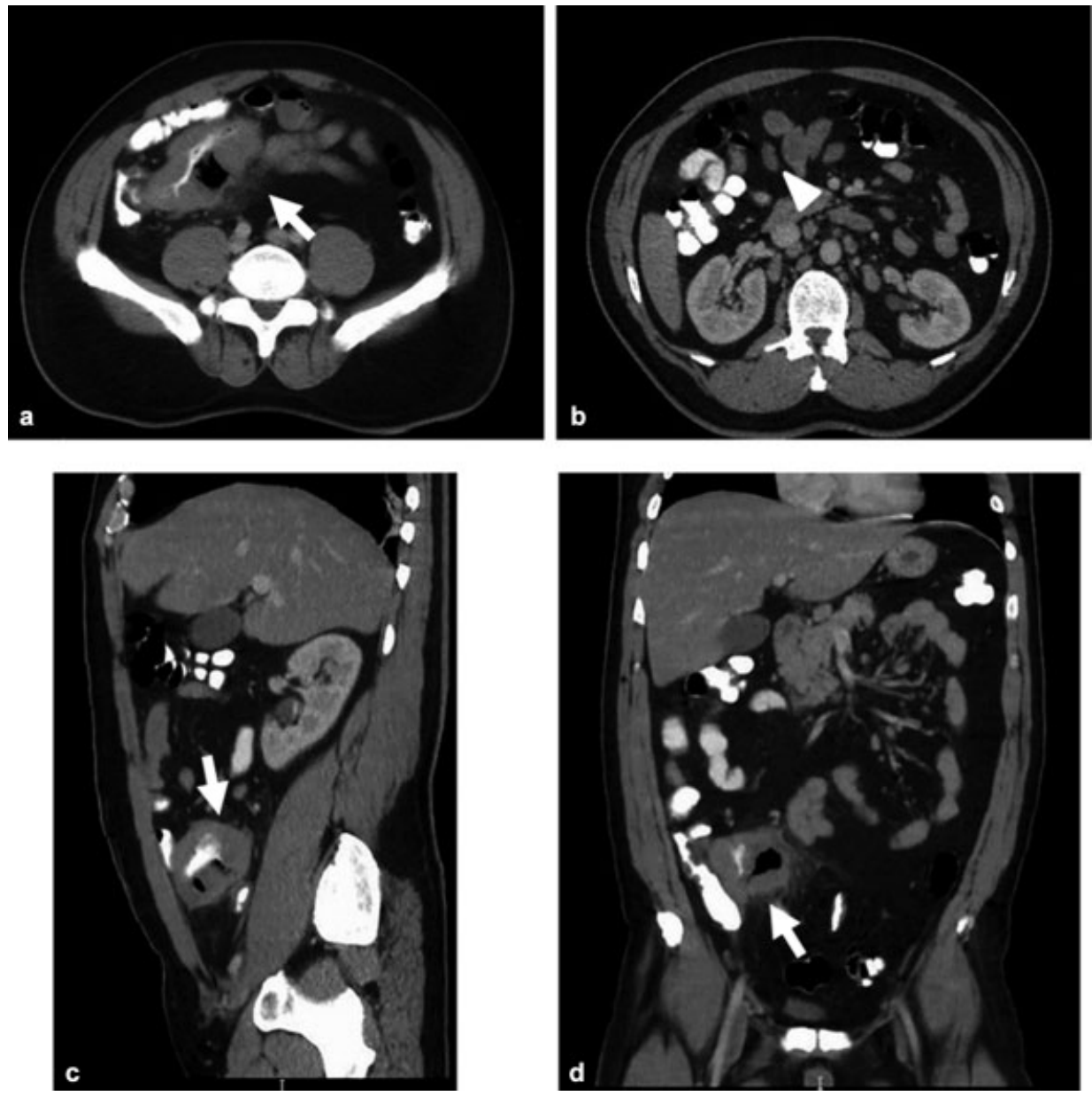

Fig. 2 TC. Cortes axiales muestran afectación segmentaria del íleon terminal con engrosamiento mural circunferencial e imágenes aéreas en su interior, asociado a alteración de la densidad de la grasa adyacente (flecha) (a y b). Imágenes ganglionares a nivel del mesenterio (cabeza de flecha). Cortes sagital y coronal en los que se observa el engrosamiento de la pared del íleon distal y el aire mural (c y d). 


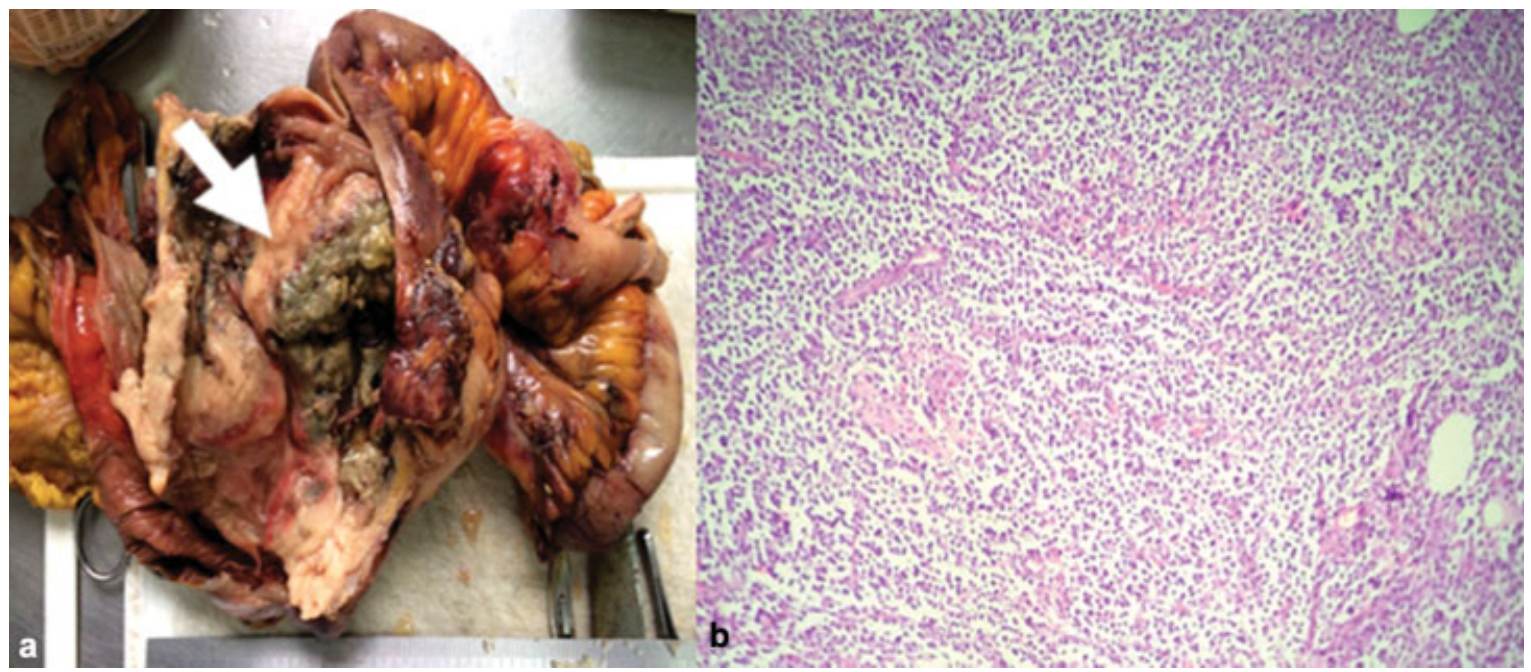

Fig. 3 Pieza quirúrgica de hemicolectomía derecha (a). Anatomía patológica (tinción H-E), se observa proliferación linfoide difusa que borra la arquitectura preexistente, consistente en células monótonas de aspecto linfoide con núcleos de cromatina irregular y escaso citoplasma: compatible con proceso linfoproliferativo (b).

El LB es un proceso linfoproliferativo maligno de rápida evolución, con una tasa de duplicación muy elevada. Cuando se manifiesta clínicamente en adultos, en general es una lesión voluminosa con compromiso local extenso que requiere tratamiento quirúrgico seguido de quimioterapia agresiva debido a su mal pronóstico. ${ }^{6,7}$ El LB puede surgir en el marco de una IDCV, inmunodeficiencia primaria más común, caracterizada por una producción reducida de inmunoglobulina que predispone a infecciones, mayor susceptibilidad a enfermedades autoinmunes y granulomatosas y al desarrollo de malignidad, especialmente LNH de células B. Se cree que la IDCV promueve la linfomagénesis por defecto de la vigilancia inmune (incluidas las células B infectadas con virus oncogénicos) y el fracaso de la eliminación del antígeno que conduce a la estimulación crónica de las células $B$, factores que también parecerían contribuir en la patogénesis de $\mathrm{LB}^{8,9}$

Los LNH de células B suelen presentarse con compromiso extranodal y a diferencia de los linfomas en otros defectos inmunes congénitos, su presentación es más común en sujetos entre la cuarta a séptima década de la vida, presentando un riesgo de 12 a 18 veces mayor que la población general y constituyendo la principal causa de morbimortalidad. ${ }^{8,10}$ A pesar de la incidencia elevada de LNH en IDCV, su asociación con el LB ha sido reportada en muy poca bibliografía hasta la actualidad.

\section{Agradecimientos}

A la Dra. Verónica Fanjul, Servicio de Anatomopatología, Clínica Colón Mar del Plata.

\section{Confidencialidad de los datos}

Los autores declaran que han seguido los protocolos de su centro de trabajo sobre la publicación de datos de pacientes y que todos los pacientes incluidos en el estudio han recibido información suficiente y han dado su consentimiento informado por escrito para participar en dicho estudio.

\section{Conflicto de Intereses}

Los autores del trabajo declaran como posible conflicto de interés, la financiación del estudio por Imágenes MDQ.

\section{Bibliografía}

1 Ghimire P, Wu GY, Zhu L. Primary gastrointestinal lymphoma. World J Gastroenterol 2011;17(06):697-707

2 Ghai S, Pattison J, Ghai S, O'Malley ME, Khalili K, Stephens M. Primary gastrointestinal lymphoma: spectrum of imaging findings with pathologic correlation. Radiographics 2007;27 (05):1371-1388

3 Lewis RB, Mehrotra AK, Rodríguez P, Manning MA, Levine MS. From the radiologic pathology archives: gastrointestinal lymphoma: radiologic and pathologic findings. Radiographics 2014;34(07):1934-1953

4 Chua I, Quinti I, Grimbacher B. Lymphoma in common variable immunodeficiency: interplay between immune dysregulation, infection and genetics. Curr Opin Hematol 2008;15(04): 368-374

5 Sendra-Fernández C, Pizarro-Moreno Á, Silva-Ruiz P, MejíasManzano MA. Linfoma de Burkitt con extensa afectación ileocolónica. Presentación como masa abdominal de crecimiento rápido. Gastroenterol Hepatol 2017;40(04): 288-290

6 González Álvarez JR, Rodríguez Hernández MA, Cordero AC, Rodríguez Hernández Z, Rodríguez Ramirez EA. Linfoma de Burkitt abdominal. Rev Cienc Méd 2014;18(02):337-344

7 Bautista-Quach MA, Ake CD, Chen M, Wang J. Gastrointestinal lymphomas: Morphology, immunophenotype and molecular features. J Gastrointest Oncol 2012;3(03):209-225

8 Polizzotto MN, McComish JS, Dawson MA, Opat SS, ColeSinclair MF. Burkitt lymphoma in the setting of common variable immunodeficiency. Ann Hematol 2009;88(08): 819-820

9 Taubenheim N, von Hornung M, Durandy A, et al. Defined blocks in terminal plasma cell differentiation of common variable immunodeficiency patients. J Immunol 2005;175(08): 5498-5503

10 Cunningham-Rundles C. The many faces of common variable immunodeficiency. Hematology (Am Soc Hematol Educ Program) 2012;2012:301-305 